\title{
Can pulsed ultrasound increase tissue damage during ischemia? A study of the effects of ultrasound on infarcted and non-infarcted myocardium in anesthetized pigs
}

\author{
Göran K Olivecrona1 ${ }^{1}$, Bjarne Madsen Härdig*1, Anders Roijer ${ }^{1}$, \\ Mattias Block ${ }^{2}$, Edgars Grins ${ }^{3}$, Hans W Persson ${ }^{4}$, Leif Johansson ${ }^{2}$ and \\ Bertil Olsson ${ }^{1}$
}

Address: ${ }^{1}$ Department of Cardiology, Lund University, SE-22185 Lund, Sweden, ${ }^{2}$ Department of Pathology, Lund University, SE-22100 Lund, Sweden, ${ }^{3}$ Departement of Anaesthesiology, Lund University, SE-22100 Lund, Sweden and ${ }^{4}$ Electrical Measurements, Lund Institute of Technology, SE-22100 Lund, Sweden

Email: Göran K Olivecrona - Goran.Olivecrona@med.lu.se; Bjarne Madsen Härdig* - bjarne.madsen-hardig@med.lu.se; Anders Roijer - anders.roijer@med.lu.se; Mattias Block - Mattias.Block@vgregion.se; Edgars Grins - Edgars.Grins@skane.se; Hans W Persson - hwp@elmat.lth.se; Leif Johansson - Leif.Johansson@pat.lu.se; Bertil Olsson - Bertil.Olsson@med.lu.se

* Corresponding author

Published: 15 April 2005

BMC Cardiovascular Disorders 2005, 5:8 doi:I0.1 |86/I47|-226I-5-8

This article is available from: http://www.biomedcentral.com/| $47|-226| / 5 / 8$

(C) 2005 Olivecrona et al; licensee BioMed Central Ltd.

This is an Open Access article distributed under the terms of the Creative Commons Attribution License (http://creativecommons.org/licenses/by/2.0), which permits unrestricted use, distribution, and reproduction in any medium, provided the original work is properly cited.
Received: 10 December 2004

Accepted: 15 April 2005

\begin{abstract}
Background: The same mechanisms by which ultrasound enhances thrombolysis are described in connection with non-beneficial effects of ultrasound. The present safety study was therefore designed to explore effects of beneficial ultrasound characteristics on the infarcted and noninfarcted myocardium.

Methods: In an open chest porcine model $(n=17)$, myocardial infarction was induced by ligating a coronary diagonal branch. Pulsed ultrasound of frequency I $\mathrm{MHz}$ and intensity $0.1 \mathrm{~W} / \mathrm{cm}^{2}\left(\mathrm{I}_{\text {SATA }}\right)$ was applied during one hour to both infarcted and non-infarcted myocardial tissue. These ultrasound characteristics are similar to those used in studies of ultrasound enhanced thrombolysis. Using blinded assessment technique, myocardial damage was rated according to histopathological criteria.

Results: Infarcted myocardium exhibited a significant increase in damage score compared to noninfarcted myocardium: $6.2 \pm 2.0$ vs. $4.3 \pm 1.5$ (mean \pm standard deviation), $(p=0.004)$. In the infarcted myocardium, ultrasound exposure yielded a further significant increase of damage scores: $8.1 \pm 1.7$ vs. $6.2 \pm 2.0(p=0.027)$.

Conclusion: Our results suggest an instantaneous additive effect on the ischemic damage in myocardial tissue when exposed to ultrasound of stated characteristics. The ultimate damage degree remains to be clarified.
\end{abstract}

\section{Background}

More then 25 years ago, it was reported that ultrasound
(US) may enhance the fibrinolytic process [1]. Throughout the 1980s and 2000s, several in-vitro and in-vivo 
experiments verified and further explored this effect, using US alone [2] or as a thrombolytic adjuvant [3-13]. The concept has recently been explored in myocardial ischemia [14] and infarction [15] in humans.

The physical properties of US fields that may account for the observed profibrinolytic effects include thermal effects, the cavitation effect and micro-streaming $[8,11,16,17]$. It is, however, still unclear as to how these contribute to the profibrinolytic mechanism. Although these effects of US are beneficial in US enhanced fibrinolysis, they might be harmful to biological tissue in other circumstances, for instance, in already injured tissue. The mechanisms by which US may be potentially harmful to biological tissue are in fact similar to those described in connection with US enhanced fibrinolysis [18-24].

The possible net benefit of successful US enhanced thrombolysis in the setting of myocardial infarction is the result of an earlier reperfusion, this could be diminished by the possible unfavourable effect of US on the ischemic myocardium. We have therefore undertaken this safety study exploring the effects of exposing ischemic myocardium to US. For this purpose a porcine model was developed in which blinded histopathological examination technique was used.

\section{Methods}

\section{Transducer calibration and measurements}

Before the animal experiments, calibration and measurements of US fields were performed on the two unfocused piezoelectric transducers used (Ceram $A B$, Lund, Sweden). The transducers had a resonance frequency of 1.0 $\mathrm{MHz}$ and diameter $16 \mathrm{~mm}$. The transducers were excited by an electronic system consisting of a function generator (HP 3314A, Hewlett-Packard, Washington, USA) and a RF power amplifier (ENI 240L, ENI, Rochester, New York, USA).

\section{Electronic scale measurements}

Measurements to determine the total radiation force were performed, using an electronic scale (Model UPT-DT-1, OHMIC Instrumental Co, St Michaels, Maryland, USA). US of $1 \mathrm{MHz}$ and a spatial-averaged, temporal-averaged intensity $\left(I_{\text {SATA }}\right)$ of $1 \mathrm{~W} / \mathrm{cm}^{2}$ was sent as continuous wave and US of $1 \mathrm{MHz}$ and a intensity of $1 \mathrm{~W} / \mathrm{cm}^{2}\left(\mathrm{I}_{\mathrm{SATA}}\right)$ was sent as pulsed wave (one burst of 100 pulses per millisecond). The continuous US exposure constituted a reference measurement and was only used in the electronic scale measurements.

\section{Hydrophone measurements}

US of $1 \mathrm{MHz}$ and an intensity of $1 \mathrm{~W} / \mathrm{cm}^{2}\left(I_{\mathrm{SATA}}\right)$ was sent as pulsed wave (one burst of 100 pulses per millisecond). Measurements were performed by scanning with a polyvi- nylidene fluoride membrane hydrophone, (GEC-Marconi Hydrophone Type Y-34-3598, Calibrated at National Physical Laboratory, Teddington, England) to determine the Mechanical Index (MI), the peak compressional pressure, rarefactional pressure and the maximal spatial peak temporal average Intensity $\left(I_{\text {SPTA }}\right)$. The signal was registered on an oscilloscope (Tektronix TDS 360, Tektronix UK, Ltd. Berkshire, United Kingdom).

Measurements were also performed of the distribution of the US field yielded by a comparable transducer as used in the study. Scanning was performed with a $0.5 \mathrm{~mm}$ diameter needle hydrophone and amplifier (Precision Acoustic LTD. United Kingdom). From the oscilloscope, digitised signals were transferred into a computer program based on Lab-View software (Department of Electrical Measurements, Lund Institute of Technology, Lund, Sweden). The computer-controlled scanning-system enabled the hydrophone to be translated along three orthogonal axes $(\mathrm{X}, \mathrm{Y}$ and $Z$ ). Scanning was performed over an area of $80 \times 30$ $\mathrm{mm}^{2}$ in the $\mathrm{Y}$ and $\mathrm{Z}$-directions starting close to the transducer surface.

\section{Temperature measurements}

Control measurement was performed of pulsed US exposure effects on temperature rise on non-circulated pig myocardium. One $0.5 \mathrm{~mm}$ temperature probe was placed $1.5 \mathrm{~cm}$ inside an extracted pig myocardial muscle $(3.0 \mathrm{~cm}$ thick) with no circulation [25]. The myocardial muscle was then placed in a degassed water bath that was heated to $37^{\circ} \mathrm{C}$. The US transducer was placed $1.5 \mathrm{~cm}$ perpendicular to the myocardial muscle surface and centred to the temperature probe. Pulsed US exposure started when water bath and muscle reach equivalent temperature. US of $1 \mathrm{MHz}$ and an intensity of $1 \mathrm{~W} / \mathrm{cm}^{2}\left(\mathrm{I}_{\mathrm{SATA}}\right)$ was sent as pulsed wave (one burst of 100 pulses per millisecond) during one hour. Simultaneous temperature measurement was performed inside the myocardial muscle and in the surrounding water bath once every half-second during the one hour of pulsed US exposure.

\section{Animal preparation}

The study was approved by the Ethical Committee of the University of Lund (approval M246/91). Seventeen 25$30 \mathrm{~kg}$ Swedish landscape pigs were used in the study. Anaesthesia was induced with $5-10 \mathrm{ml}(25 \mathrm{mg} / \mathrm{ml})$ sodium pentothal (Pentothal Natrium, Abbot Scandinavia $A B$, Sweden) intravenously (I.V.) before tracheotomy. The pigs were mechanically ventilated (Serviventilator 900 B, Siemens Elema, Sweden). Access to circulation was maintained through one arterial entrance and at least two venous lines. Blood pressure was continuously monitored through the arterial line. Anaesthesia was maintained with ketamine (Ketalar, Parke-Davis, Division of Warener Lambert Nordic AB, Sweden) at a dose of $5 \mathrm{mg} / \mathrm{Kg} / \mathrm{min}$ 
I.V., and pancurone (Pavulone, Organon Teknika AB, Sweden) at a dose of $0.3 \mathrm{mg} / \mathrm{Kg} / \mathrm{min}$ I.V. Following sternotomi, the pericardium was incised and its borders along the incision line sutured to the skin overlying the sternal edges. A large proximal diagonal branch of the left anterior descending artery (LAD) was ligated to induce myocardial infarction.

\section{Transducer and US exposure}

Following 1 hour of coronary ligation, the US transducers were applied. Each of the two transducers was fixed to a universal joint attached to a small steel pipe on a stand. The transducers were thus in a fixed position, and placed approximately $1.5 \mathrm{~cm}$ from the epicardium.

The transducer at the non-infarcted myocardium was placed to radiate part of the anterior/apical free wall of the left ventricle, while the transducer radiating part of the infarcted myocardium was placed in the mid/basal region of the anterior portion of left ventricle, corresponding to the myocardial region perfused by the ligated large diagonal branch of the LAD (Figure 1). US gel (Clinical, Diagramm Halbach AG, Germany) was then applied to the entire anterior portion of the heart to ensure adequate sound wave transmission to the epicardium. Due to loss of gel during the procedure, additional gel was deposited repeatedly during the one hour transducer and pulsed US exposure period.

The US radiation applied over the myocardial areas was, pulsed US of frequency $1 \mathrm{MHz}$ and intensity of $1 \mathrm{~W} / \mathrm{cm}^{2}$. Each millisecond, a burst of one hundred cycles was sent, equivalent to a duty cycle of $10 \%$ and a resulting intensity of $0.1 \mathrm{~W} / \mathrm{cm}^{2}\left(I_{\text {SATA }}\right)$.

The experiment was designed to illustrate possible injury effects of pulsed US exposure, mechanical handling of the hearts and application of transducers alone. The altogether 68 tissue samples from the 17 pig hearts were thus used as follows:

A) 17 samples of non-infarcted myocardium without any exposure.

B) 4 samples of non-infarcted myocardium exposed to transducer alone.

C) 13 samples of non-infarcted myocardium exposed to pulsed US.

D) 17 samples of infarcted myocardium without any exposure.

E) 8 samples of infarcted myocardium exposed to transducer alone.
F) 9 samples of infarcted myocardium exposed to pulsed US.

\section{Tissue preparation and histopathological evaluation}

After one hour of applied pulsed US radiation or transducer exposure, epicardial sutures were placed at two locations under the transducers, to indicate the diameter of the exposed area and indicate areas were tissue samples should be removed. The pigs were then immediately given $10 \mathrm{ml}$ of potassium $\left(2 \mathrm{mmol} / \mathrm{ml}\right.$, Addex-Kalium ${ }^{\mathrm{TM}}$, Pharmacia \& Upjohn $\mathrm{AB}$, Sweden) intravenously to induce ventricular fibrillation, which occurred momentarily following administration. The great vessels were then clamped and cut by scalpel, while the veins were ligated and cut by scissors. The entire heart was then extracted intact followed by immediate removal of tissue samples. During the procedure, care was taken to minimize traumatic handling of the heart. Transmural samples, 5-10 $\mathrm{mm}$ in diameter, were then carefully removed with a scalpel. Following excision, the tissue samples were prepared for histopathological evaluation. From each sample, three slides were cut from the formalin fixed and paraffin embedded blocks and stained with Hematoxylin-Eosin (Van Gieson, and Phosphor Tungistic Acid Hematoxylin, PTAH) respectively. The samples were then examined by routine light microscopy in $10 \times, 20 \times$ and $40 \times$ enlargement. An experienced pathologist examined all slides in a blinded fashion unaware of whether the tissue samples were from infarcted, or non-infarcted tissue, or if it had, or had not been exposed to US. In the microscopic evaluation only the common signs of tissue damage, seen during the early phase of myocardial infarction, were observed [26].

The parameters evaluated for damage score were as follows:

1) Eosinophilic changes in the myocyte, (Ischemia)

2) Reduction and/or loss of cross striation, (Loss of striation)

3) Coagulation necrosis, (Necrosis)

4) Infiltration of polymorphonuclear cells, (PMN)

All parameters were scored from 0 to 3 , where 0 indicated no damage, 1 indicated minimal change, 2 intermediate changes and 3 extensive changes. Analysis was made of the damage score for each of the parameters (Ischemia, Loss of striation, Necrosis and PMN) and the total sum of damage scores (TDS) of the four parameters. Thus, the TDS had a minimum possible total damage score of 0 and a maximum possible total damage score of 12 . 


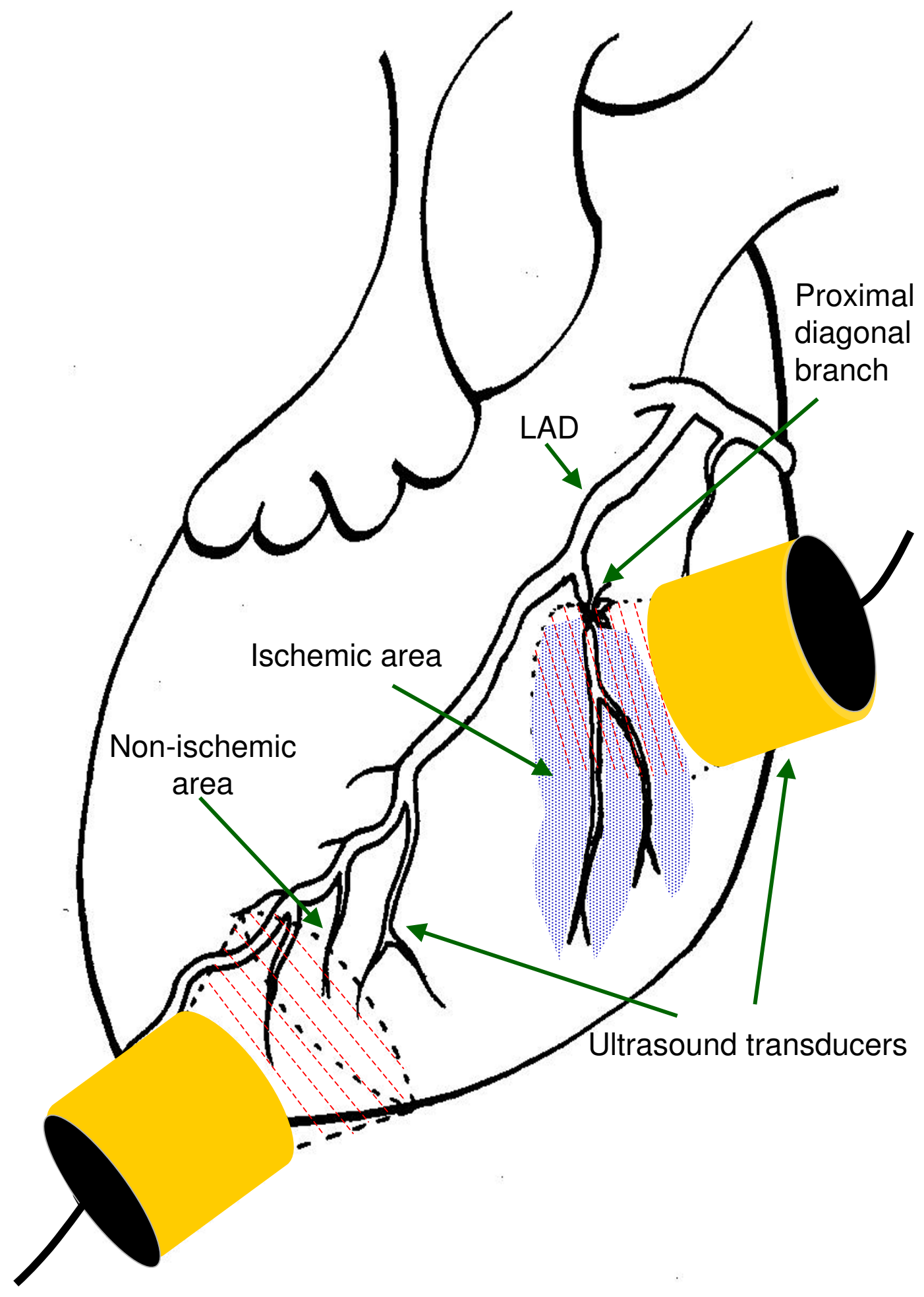

Figure I

Experimental setup. Schematic depiction of the open chest porcine model with the ligated diagonal branch of the left anterior descending artery. The shading indicates the extent of ischemic tissue. Ultrasound transducers are applied over ischemic as well as non-ischemic tissue. 


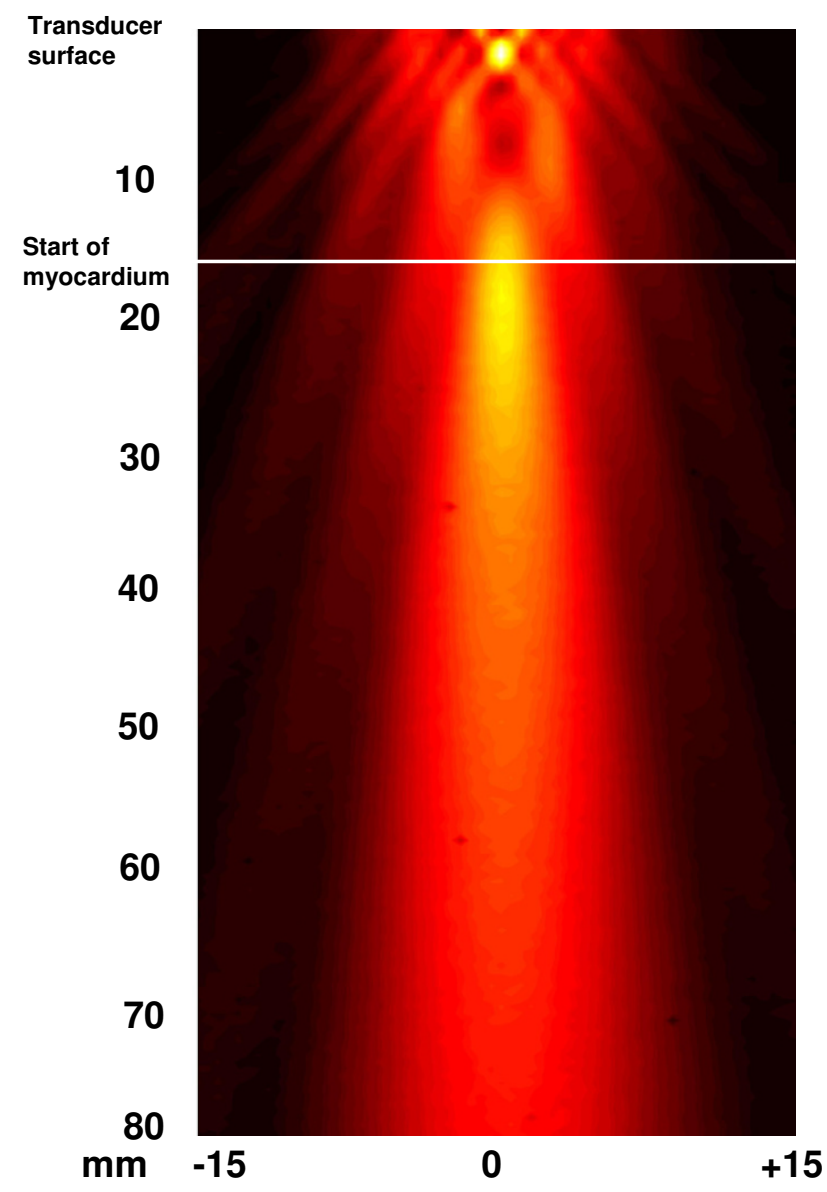

\section{Figure 2}

Ultrasound field distribution. The field distribution for the transducers is shown, but no exact values of intensity was measured. Scanning was performed over an area of $80 \times$ $30 \mathrm{~mm}^{2}$ in the $Y$ and Z-directions starting close to the transducer surface. The transducer surface and the start of myocardium is mark.

\section{Statistical analysis}

The TDS of all groups were analysed to estimate the normal distribution by Chi-square test for goodness of fit. The statistical analysis compared the TDS scores in two ways: by paired Students t-test for the comparison of effects in individual animals and Student t-test for group comparison. A p value of less than 0.05 was considered statistically significant.

\section{Results}

\section{Transducer calibration and measurements}

Electronic scale measurements

In the balance measurements, using continuous wave US, the US power supply was set to yield an acoustic power value of $2.0 \mathrm{~W}$, corresponding to an intensity of $1 \mathrm{~W} / \mathrm{cm}^{2}$ $\left(I_{\text {SATA }}\right)$ adjusted to the area of the transducers. Using pulsed wave (10\% duty cycle) US at the same power supply the intensity was $0.19 \mathrm{~W}$, which correspond to an intensity of $0.1 \mathrm{~W} / \mathrm{cm}^{2}\left(I_{\text {SATA }}\right)$.

\section{Hydrophone measurements}

In the membrane hydrophone measurements the $I_{\mathrm{SPTA}}$ was measured to $460 \mathrm{~mW} / \mathrm{cm}^{2}$ and the MI was calculated [27] to be 0.41 at a distance of $3.0-3.5 \mathrm{~cm}$ from the surface of the transducer. At the same distance the peak compressional pressure was measured to a value of $0.41 \mathrm{Mega}$ Pascal (MPa) and the peak rarefactional pressure was 0.41 $\mathrm{MPa}$. The needle hydrophone measurement was performed in degassed water to explore field distribution for the used transducers, the distribution was determined but exact values of intensity were not measured (Figure 2).

\section{Temperature measurements}

During the first $20 \mathrm{~min}$ of pulsed US exposure to the extracted myocardial muscle an increasing temperature difference was seen between the non-circulated pig myocardium and the surrounding water bath. After $20 \mathrm{~min}$ of exposure the temperature reached a steady state difference of $0.5^{\circ} \mathrm{C}$ (Table 1 ).

Table I: Temperature measurements The temperature increase for non-circulated pig myocardium during pulsed ultrasound exposure. Temperature was measured every 0.5 -second during I hour and $27 \mathrm{~min}$. Temperature at different time interval is presented as mean \pm standard deviation ${ }^{\circ} \mathrm{C}$. Differences in temperature between the exposed myocardium and surrounding water bath are also shown.

\begin{tabular}{|c|c|c|c|}
\hline 0.5 sec/intervals & $\begin{array}{c}\text { Inside water bath } \\
\text { Mean } \pm \text { SD }\end{array}$ & $\begin{array}{c}\text { Inside heart muscle } \\
\text { Mean } \pm \text { SD }\end{array}$ & Difference degrees $\mathbf{C}$ \\
\hline 5 min steady state & $36.8 \pm 0.12$ & $36.8 \pm 0.03$ & 0.0 \\
\hline During first 2 min US & $36.7 \pm 0.12$ & $36.9 \pm 0.05$ & 0.2 \\
\hline During first $5 \mathrm{~min}$ US & $36.8 \pm 0.12$ & $37.0 \pm 0.07$ & 0.2 \\
\hline During first $10 \mathrm{~min} U S$ & $36.8 \pm 0.12$ & $37.1 \pm 0.08$ & 0.3 \\
\hline $10-20$ min US & $36.7 \pm 0.11$ & $37.2 \pm 0.03$ & 0.4 \\
\hline $20-40$ min US & $36.7 \pm 0.10$ & $37.2 \pm 0.03$ & 0.5 \\
\hline $40-60$ min US & $36.7 \pm 0.10$ & $37.1 \pm 0.03$ & 0.5 \\
\hline $20 \mathrm{~min}$ after US termination ( $2 \mathrm{~min}$ ) & $36.6 \pm 0.12$ & $36.7 \pm 0.03$ & 0.1 \\
\hline
\end{tabular}




\section{Physiologic monitoring}

All animals were stable in circulation during the experiments and were under supervision of both anaesthesia and cardiology expertise during the whole experiment period. An estimation of the infarcted area is shown in figure 1. No exact measurement of the size of infarcted area was however performed.

\section{Histopathological evaluation}

Examples of the different score grades are shown in figure 3. Signs of myocardial damage were noted already in all 17 perfused tissue specimen untouched by an US transducer, TDS being $4.3 \pm 1.5$ (mean \pm standard deviation). In comparison, the infarcted tissue, untouched by any US transducer, had a significantly higher damage score, irrespective if comparison used the paired difference technique $(\mathrm{p}<0.001)$ or Student t-test for group comparison, $6.2 \pm 2.0$ vs. $4.3 \pm 1.5(\mathrm{p}=0.004)$. There was a further significant augmentation of the tissue injury in the infarcted myocardium exposed to US, also evidenced by paired difference ( $\mathrm{p}=0.026)$ and Student t-test for group comparison $8.1 \pm 1.7$ vs. $6.2 \pm 2.0(\mathrm{p}=0.027)$. The individual damage scores and statistical analyses for all groups are shown in figure 4 .

\section{Control experiments}

Following US exposure of non-infarcted myocardium, there was a significant increase in TDS, from $4.3 \pm 1.5$ to $5.8 \pm 1.7$ ( $\mathrm{p}=0.015$, Student t-test for group comparison) .

The application of transducer exposure alone did not significantly affect the damage caused by myocardial infarction, evidenced by the TDS $6.2 \pm 2.0$ vs. $6.6 \pm 2.1(\mathrm{p}=$ 0.662 , Student t-test for group comparison and $\mathrm{p}=0.244$ if paired Student t-test was used).

\section{Discussion}

The theoretical possibility of exaggeration of myocardial damage in non-perfused tissue following pulsed US exposure prompted the present analysis of the effect of US on the ischemic myocardium. We chose an open chest porcine model with an induced myocardial infarction and applied US to test our hypothesis that lengthy US exposure on ischemic myocardial tissues could potentially be harmful, even when used within limits hitherto considered safe in cardiac exposures [28,29]

The histopathological diagnosis of tissue damage during the first hour of coronary artery occlusion is based on subtle findings. The assessment of cardiac damage used is therefore not specific as a in a fully developed infarction. Furthermore, we found a notable amount of damage already in the samples from the non-infarcted myocardium that not were exposed to transducer or US, a finding which could be explained by stress-induced damage [30-
32] as well as mechanical handling of the heart during removal. The genuine effect of the 2-hour long lasting ischemia shows however a significant increase in the total damage score by $45 \%$. US exposure of the infarcted myocardium resulted in a significant further increase of the total damage score by another $30 \%$.

\section{Possible mechanisms of ultrasonic injuries}

High Intensity US causes damage in biological tissues through three mechanisms; thermal, mechanical and cavitational injuries [18-24]. The physical properties of US fields which may account for the profibrinolytic effects observed are thermal effects, the cavitation effect and micro-streaming $[8,11,16,17]$. As earlier stated, the USinduced damage in biological tissues may develop by the same mechanisms that enhance fibrinolysis.

Heat produced in perfused tissues exposed to US within safe levels would under ordinary circumstances mainly be lost to the circulation. In ischemic tissues, the reduced circulation may thus decrease the heat-loss ability during US exposure resulting in undesirable heating and creating a thermal injury [22]. However, in the present study, temperature measurements in the non-circulated myocardial tissue illustrated only a small increase $\left(0.5^{\circ} \mathrm{C}\right)$, well within in the limits of now used safety rules.

High frequency US exposure of circulated tissue has been shown to induce a mild increase in interstitial oedema, an accumulation of polymorphonuclear cells [33], oxidative stress in endothelial cells [34] and increased cell lysis and apoptosis in human myelomonocytic leukaemia cells [35]. It has been hypothesized that the effects may be caused by radiation force [35] and other non-thermal effects [34]. US at similar exposure settings as used in the present study have been shown to produce necrotic and cellular damage in epidermis layers in goldfish [25]. Increasing sonication duration resulted in a progressively greater damage score. Damage was also shown to gradually propagate inwards the cell layers with increased sonication duration. It was concluded that the damage produced was caused by cavitational injury [25]. Anatomical structural differences and the age of the animal have also been shown to affect the sensitivity for US exposure [21], although the role of the age dependence remains unclear[24].

In conclusion, available data are unable to disclose the true mechanism of the myocardial injury induced by pulsed US. Finally, the development of ischemic myocardial damage over time is evidenced by different and unspecific indicators of damage, some being reversible [36]. It is therefore not possible to estimate how the myocardial tissue in the present study would be affected after a fully developed infarction. 


\section{Examples of histopathological examination}
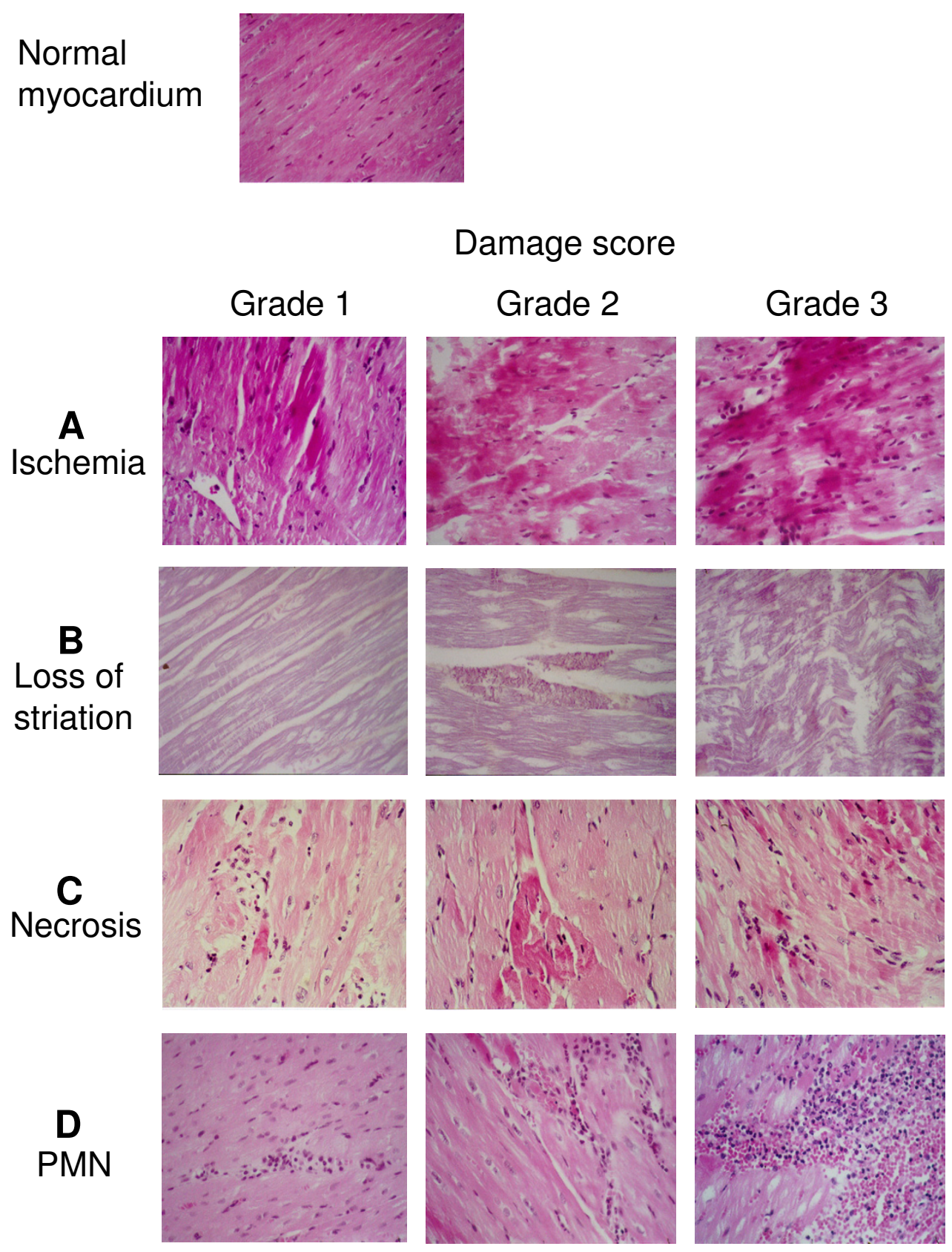

\section{Figure 3}

Examples of histopathological indicators. Examples of the various histopathological indicators of tissue damage at different damage scores: $\mathrm{A}=$ Eosinophilic changes in the myocyte (Ischemia), $\mathrm{B}=$ Reduction and/or loss of cross striation (Loss of striation), $C=$ Coagulation necrosis (Necrosis), D = Infiltration of poly-morphonuclear cells (PMN). The estimated degree of damage in each sample is graded in a $0-3$ scale. For further information see text. 
Total myocardial damage scores observed by histopathological analysis

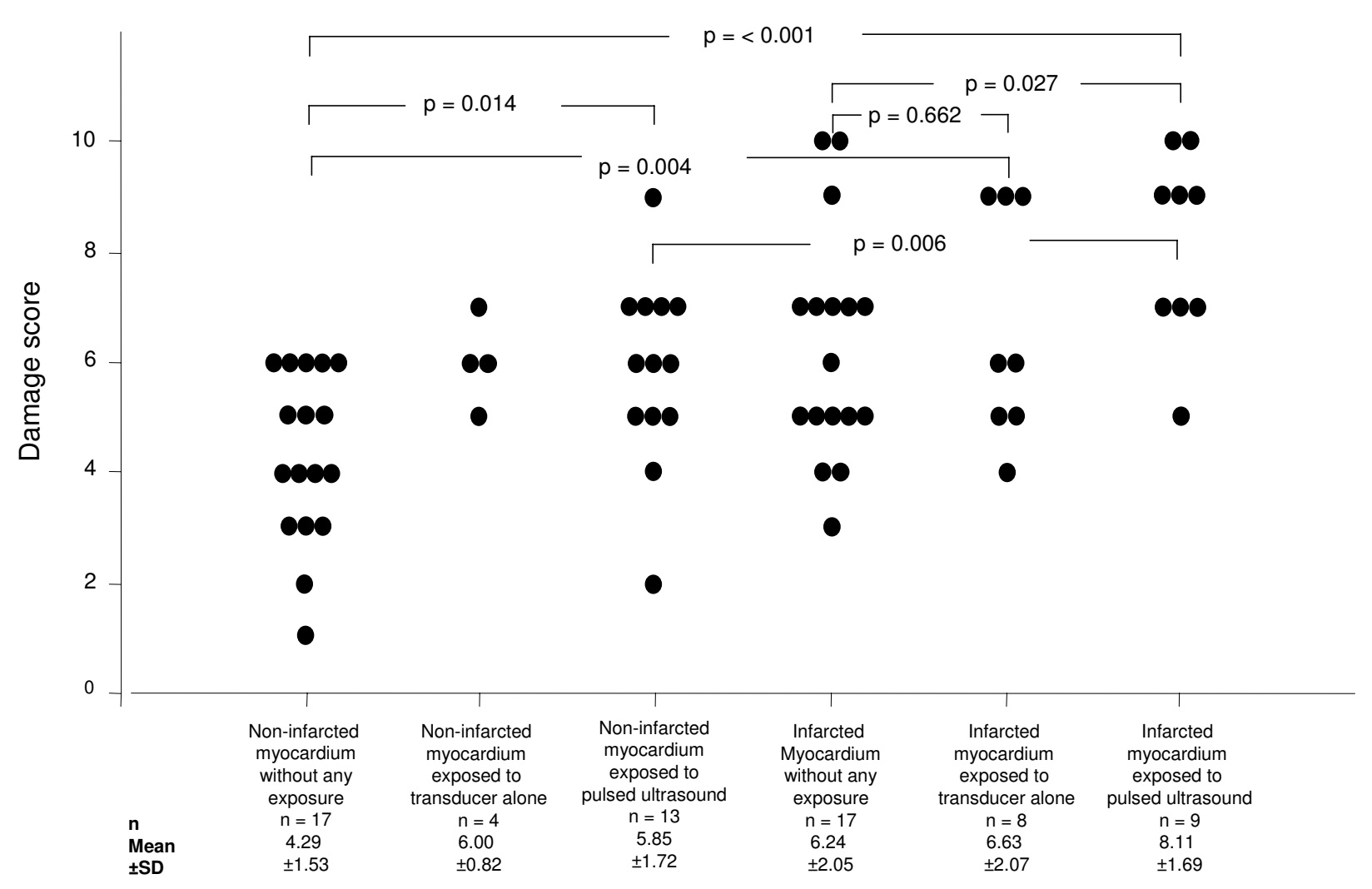

Figure 4

Individual total damage score and statistical analysis. The dot-plot shows the total damage scores obtained in 64 individual tissue samples from the 6 different myocardial areas. Statistical comparisons of the total damage scores (TDS) were performed using the Students t-test for group comparison. A p value of less than 0.05 was considered statistically significant.

\section{Relevance of study results}

Multiple studies of the beneficial effects of US used to enhance thrombolysis have been conducted in different animal models, both in the venous and arterial systems $[7,8,12,33,37-45]$. The progress in the area has also reached humans in the clinical setting. Thus, a prospective controlled study of US augmentation of thrombolysis in myocardial ischemia failed to verify a beneficial effect [14]. In fact, the number of ischemic complications increased following US exposure. In contrast, no undesirable effects were however noticed in 25 patients with myocardial infarction, who received traditional thrombolytic treatment with adjunctive US exposure [15]. Interestingly, early and complete arterial recanalisation was noted in selected patients with stroke, who received thrombolytic treatment and whose cerebral arterial blood flow was followed with transcranial Doppler technique [46].
The result of our study clearly obviates the importance of evaluating the potentially non-beneficial effects of US aiming at enhancement of thrombolysis. In the setting of US exposure during cerebral ischemia, and at US energy levels verified to be beneficial in experimental studies of thrombolysis [7], no detectable additive damage was however verified following exposure of pulsed US [47].

\section{Study limitations}

Two control experiments were carried out. Firstly, we verified that fixation of the transducer and application of US gel close to the infarcted myocardium did not significantly affect the TDS. Secondly, we explored the effect of US on perfused myocardium. Interestingly there were significant signs of myocardial damage also in this presumed healthy tissue following US exposure. 
The sensitivity for stress-induced damage in the pig limits this study considerably and makes the interpretation of data more difficult. Still, the total damage score after US exposure significantly exceed damage scores in the unexposed infarcted tissue samples.

No threshold measurements were performed, however the total US energy we used is in the order of 10 times higher than required to enhance the thrombolysis invitro[6]. Neither was the temperature monitored in the areas during exposure to US. The low number of samples $(n=4)$ in the group of non-infarcted myocardium exposed to transducer alone is the result of protocol misinterpretation, unfortunately necessitating the exclusion of these data from the statistical comparison.

\section{Conclusion}

Lengthy pulsed US exposure of low intensity exerting beneficial pro-fibrinolytic effects in the setting of thrombolysis may increase instantaneous myocardial damage.

\section{List of abbreviations used}

US: Ultrasound

$I_{\text {SATA }}$ : Spatial-Averaged, Temporal-Averaged Intensity

MI: Mechanical Index

$I_{\text {SPTA }}:$ Spatial-Peak Temporal Average Intensity

LAD: Left anterior descending artery

TDS: Total damage score

\section{Competing interests}

The author(s) declare that they have no competing interests.

\section{Authors' contributions}

GO designed the investigation, did the surgical and ultrasound experiments, performed the statistical analysis and interpretation of the results, as well as the preparation of the manuscript.

BMH performed the statistical analysis and interpretation of the results, as well as the preparation of the manuscript.

AR was involved in the design of the investigation and interpretation of the results and approved the final manuscript.

MB was involved in the histopathological evaluation and interpretation of the results and approved the final manuscript.
EG did the surgical and ultrasound experiments and approved the final manuscript.

HWP was involved in the designed the investigation and interpretation of the results, as well as the preparation of the manuscript.

LJ was involved in the histopathological evaluation and interpretation of the results and approved the final manuscript.

SBO supervised and designed the investigation as well as participated in the preparation of the manuscript.

All authors read and approved the final manuscript.

\section{Acknowledgements}

The project has been supported with grants from

The Swedish Medical Research Council (K98-19X), Swedish Heart and Lung Foundation (Hjärt-Lung Fonden), the Thorsten Westerström Foundation (Thorsten Westerströms stiftelse) and Franke and Margareta Bergqvist foundation (Franke och Margareta Bergqvist stiftelse).

We appreciate the invaluable advice and recommendations from Professor Karel Maršál, Department of Gynecology and Obstetrics, Lund University Hospital, Sweden.

We will also want to thank Johan Persson at the Department of Orthopedics, Lund University, Sweden for professional advise and help with the temperature measurements.

\section{References}

I. Trubestein G, Engel C, Etzel F, Sobbe A, Cremer H, Stumpff U: Thrombolysis by ultrasound. Clin Sci Mol Med Suppl 1976, 3:697s-698s.

2. Cintas $\mathrm{P}$, Le Traon AP, Larrue $\mathrm{V}$ : High rate of recanalization of middle cerebral artery occlusion during $2-\mathrm{MHz}$ transcranial color-coded Doppler continuous monitoring without thrombolytic drug. Stroke 2002, 33:626-8.

3. Atar S, Luo H, Birnbaum Y, Nagai T, Siegel RJ: Augmentation of invitro clot dissolution by low frequency high-intensity ultrasound combined with antiplatelet and antithrombotic drugs. J Thromb Thrombolysis 200I, I I:223-8.

4. Pfaffenberger S, Devcic-Kuhar B, El-Rabadi K, Groschl M, Speid WS, Weiss TW, Huber K, Benes E, Maurer G, Wojta J, Gottsauner-Wolf $\mathrm{M}: \mathbf{2} \mathrm{MHz}$ ultrasound enhances t-PA-mediated thrombolysis: comparison of continuous versus pulsed ultrasound and standing versus travelling acoustic waves. Thromb Haemost 2003, 89:583-9.

5. Nilsson AM, Odselius R, Roijer A, Olsson SB: Pro- and antifibrinolytic effects of ultrasound on streptokinase-induced thrombolysis. Ultrasound Med Biol 1995, $21: 833-40$.

6. Olsson SB, Johansson B, Nilsson AM, Olsson C, Roijer A: Enhancement of thrombolysis by ultrasound. Ultrasound Med Biol 1994, 20:375-82.

7. Larsson J, Carlson J, Olsson SB: Ultrasound enhanced thrombolysis in experimental retinal vein occlusion in the rabbit. $\mathrm{Br} J$ Ophthalmol 1998, 82: 1438-40.

8. Kornowski R, Meltzer RS, Chernine A, Vered Z, Battler A: Does external ultrasound accelerate thrombolysis? Results from a rabbit model. Circulation 1994, 89:339-44.

9. Kimura M, lijima S, Kobayashi K, Furuhata $\mathrm{H}$ : Evaluation of the thrombolytic effect of tissue-type plasminogen activator with ultrasonic irradiation: in vitro experiment involving 
assay of the fibrin degradation products from the clot. Biol Pharm Bull 1994, 17:126-30.

10. Alexandrov AV, Demchuk AM, Felberg RA, Christou I, Barber PA, Burgin WS, Malkoff M, Wojner AW, Grotta JC: High rate of complete recanalization and dramatic clinical recovery during tPA infusion when continuously monitored with $2-\mathrm{MHz}$ transcranial doppler monitoring. Stroke 2000, 31:610-4.

II. Akiyama M, Ishibashi T, Yamada T, Furuhata H: Low-frequency ultrasound penetrates the cranium and enhances thrombolysis in vitro. Neurosurgery 1998, 43:828-32. discussion 832-3

12. Daffertshofer M, Huang Z, Fatar M, Popolo M, Schroeck H, Kuschinsky W, Moskowitz MA, Hennerici MG: Efficacy of sonothrombolysis in a rat model of embolic ischemic stroke. Neurosci Lett 2004, 361:115-9.

13. Basta G, Lupi C, Lazzerini G, Chiarelli P, L'Abbate A, Rovai D: Therapeutic effect of diagnostic ultrasound on enzymatic thrombolysis. An in vitro study on blood of normal subjects and patients with coronary artery disease. Thromb Haemost 2004, 9I:1078-83.

14. Singh M, Rosenschein U, Ho KK, Berger PB, Kuntz R, Holmes DR Jr: Treatment of saphenous vein bypass grafts with ultrasound thrombolysis: a randomized study (ATLAS). Circulation 2003, 107:2331-6

15. Cohen MG, Tuero E, Bluguermann J, Kevorkian R, Berrocal DH, Carlevaro O, Picabea E, Hudson MP, Siegel RJ, Douthat L, Greenbaum $A B$, Echt $D$, Weaver WD, Grinfeld LR: Transcutaneous ultrasound-facilitated coronary thrombolysis during acute myocardial infarction. Am J Cardiol 2003, 92:454-7.

16. Luo H, Steffen W, Cercek B, Arunasalam S, Maurer G, Siegel RJ: Enhancement of thrombolysis by external ultrasound. Am Heart J 1993, I 25: I564-9.

17. Sakharov DV, Hekkenberg RT, Rijken DC: Acceleration of fibrinolysis by high-frequency ultrasound: the contribution of acoustic streaming and temperature rise. Thromb Res 2000, 100:333-40.

18. Barnett SB, Rott HD, ter Haar GR, Ziskin MC, Maeda K: The sensitivity of biological tissue to ultrasound. Ultrasound Med Biol 1997, 23:805-12.

19. Barnett SB, Ter Haar GR, Ziskin MC, Rott HD, Duck FA, Maeda K: International recommendations and guidelines for the safe use of diagnostic ultrasound in medicine. Ultrasound Med Biol 2000, 26:355-66.

20. Fowlkes JB, Crum LA: Cavitation threshold measurements for microsecond length pulses of ultrasound. J Acoust Soc Am I988, 83:2190-201.

21. Fowlkes JB, Holland CK: Mechanical bioeffects from diagnostic ultrasound: AIUM consensus statements. American Institute of Ultrasound in Medicine. J Ultrasound Med 2000, 19:69-72.

22. Barnett $S B$, Kossoff $G$, Edwards MJ: Is diagnostic ultrasound safe? Current international consensus on the thermal mechanism. Med J Aust 1994, 160:33-7.

23. Barnett SB, ter Haar GR, Ziskin MC, Nyborg WL, Maeda K, Bang J: Current status of research on biophysical effects of ultrasound. Ultrasound Med Biol 1994, 20:205-18.

24. O'Brien WD Jr, Simpson DG, Ho MH, Miller RJ, Frizzell LA, Zachary JF: Superthreshold behavior and threshold estimation of ultrasound-induced lung hemorrhage in pigs: role of age dependency. IEEE Trans Ultrason Ferroelectr Freq Control 2003, 50:153-69.

25. Frenkel V, Kimmel E, lger $Y$ : Ultrasound-induced cavitation damage to external epithelia of fish skin. Ultrasound Med Biol 1999, 25: 1295-303.

26. Silver M: Cardiovascular Pathology,. 2nd edition. New York: Churchill Livingstone Inc, 1560 Broadway, New York, NY 10036, USA; 1991:621-670

27. de Jong N: Mechanical index. Eur J Echocardiogr 2002, 3:73-4.

28. The American Institute of Ultrasound in Medicin (AIUM): Safety considerations for diagnostic Ultrasound. The American Institute of Ultrasound in Medicin; 1991.

29. WHO: Environmental Health Criteria 22: Ultrasound. Geneva: (WHO) 1982 [http://www.inchem.org/documents/ehc/ehcl ehc22.htm].

30. Johansson G, Jonsson L: Myocardial cell damage in the porcine stress syndrome. J Comp Pathol 1977, 87:67-74.

31. Johansson G, Jonsson L, Lannek N, Blomgren L, Lindberg P, Poupa O: Severe stress-cardiopathy in pigs. Am Heart J 1974, 87:45I-7.
32. Jonsson L, Johansson G: Cardiac muscle cell damage induced by restraint stress. Virchows Arch B Cell Pathol 1974, I 7: I- 12

33. Kashyap A, Blinc A, Marder VJ, Penney DP, Francis CW: Acceleration of fibrinolysis by ultrasound in a rabbit ear model of small vessel injury. Thromb Res 1994, 76:475-85.

34. Basta G, Venneri L, Lazzerini G, Pasanisi E, Pianelli M, Vesentini N, Del Turco S, Kusmic C, Picano E: In vitro modulation of intracellular oxidative stress of endothelial cells by diagnostic cardiac ultrasound. Cardiovasc Res 2003, 58: I56-6I.

35. Feril LB Jr, Kondo T, Takaya K, Riesz P: Enhanced ultrasoundinduced apoptosis and cell lysis by a hypotonic medium. Int $J$ Radiat Biol 2004, 80:165-75.

36. Morales C, Gonzalez GE, Rodriguez M, Bertolasi CA, Gelpi RJ: Histopathologic time course of myocardial infarct in rabbit hearts. Cardiovasc Pathol 2002, II:339-45.

37. Siegel RJ, Atar S, Fishbein MC, Brasch AV, Peterson TM, Nagai T, Pal D, Nishioka T, Chae JS, Birnbaum Y, Zanelli C, Luo H: Noninvasive, transthoracic, low-frequency ultrasound augments thrombolysis in a canine model of acute myocardial infarction. Circulation 2000, I 01:2026-9.

38. Suchkova V, Carstensen EL, Francis CW: Ultrasound enhancement of fibrinolysis at frequencies of 27 to $100 \mathrm{kHz}$. Ultrasound Med Biol 2002, 28:377-82.

39. Luo H, Nishioka T, Fishbein MC, Cercek B, Forrester JS, Kim CJ, Berglund $\mathrm{H}$, Siegel RJ: Transcutaneous ultrasound augments lysis of arterial thrombi in vivo. Circulation 1996, 94:775-8.

40. Luo H, Fishbein MC, Bar-Cohen Y, Nishioka T, Berglund H, Kim CJ, Nagai T, Birnbaum Y, Siegel RJ: Cooling System Permits Effective Transcutaneous Ultrasound Clot Lysis In Vivo Without Skin Damage. J Thromb Thrombolysis 1998, 6: I25-131.

4I. Jeon DS, Luo H, Fishbein MC, Miyamoto T, Horzewski M, Iwami T, Mirocha JM, Ikeno F, Honda Y, Siegel RJ: Noninvasive transcutaneous ultrasound augments thrombolysis in the left circumflex coronary artery-an in vivo canine study. Thromb Res 2003, I I 0:149-58

42. Ernst A, Schenk EA, Woodlock TJ, Alliger H, Gottlieb S, Child SZ, Meltzer RS: Feasibility of recanalization of human coronary arteries using high-intensity ultrasound. Am J Cardiol 1994, 73: $126-32$.

43. Birnbaum Y, Luo H, Nagai T, Fishbein MC, Peterson TM, Li S, Kricsfeld D, Porter TR, Siegel RJ: Noninvasive in vivo clot dissolution without a thrombolytic drug: recanalization of thrombosed iliofemoral arteries by transcutaneous ultrasound combined with intravenous infusion of microbubbles. Circulation 1998, 97:130-4.

44. Birnbaum Y, Luo H, Atar S, Fishbein MC, Brasch AV, Nagai T, Pal D, Nishioka T, Chae JS, Zanelli C, Peterson TM, Siegel RJ: Noninvasive transthoracic low frequency ultrasound augments thrombolysis in a canine model of acute myocardial infarction evaluation of the extent of ST-segment resolution. I Thromb Thrombolysis 200I, I I:229-34.

45. Ariani M, Fishbein MC, Chae JS, Sadeghi H, Michael AD, Dubin SB, Siegel RJ: Dissolution of peripheral arterial thrombi by ultrasound. Circulation 199I, 84: I680-8.

46. Alexandrov AV: Ultrasound-enhanced thrombolysis for stroke: clinical significance. Eur J Ultrasound 2002, I6: | 3 |-40.

47. Hardig BM, Persson HW, Gido G, Olsson SB: Does low-energy ultrasound, known to enhance thrombolysis, affect the size of ischemic brain damage? J Ultrasound Med 2003, 22: I30I-8.

\section{Pre-publication history}

The pre-publication history for this paper can be accessed here:

http://www.biomedcentral.com/1471-2261/5/8/prepub 